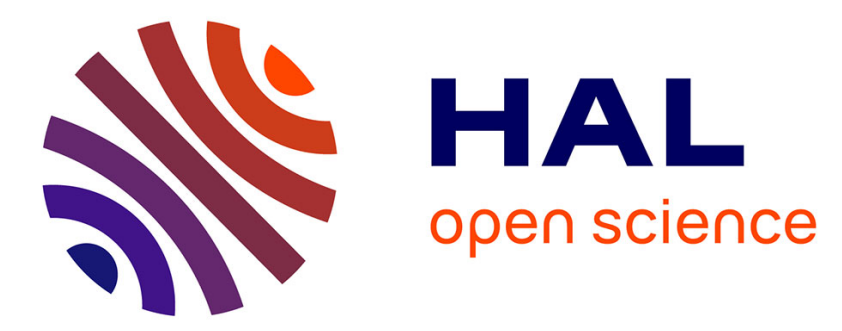

\title{
Understanding biofilm formation in intravascular device-related infections
}

Christophe Beloin, Nuria Fernández-Hidalgo, David Lebeaux

\section{To cite this version:}

Christophe Beloin, Nuria Fernández-Hidalgo, David Lebeaux. Understanding biofilm formation in intravascular device-related infections. Intensive Care Medicine, 2016, 10.1007/s00134-016-4480-7 . pasteur-01377078

\section{HAL Id: pasteur-01377078}

\section{https://hal-pasteur.archives-ouvertes.fr/pasteur-01377078}

Submitted on 6 Oct 2016

HAL is a multi-disciplinary open access archive for the deposit and dissemination of scientific research documents, whether they are published or not. The documents may come from teaching and research institutions in France or abroad, or from public or private research centers.
L'archive ouverte pluridisciplinaire HAL, est destinée au dépôt et à la diffusion de documents scientifiques de niveau recherche, publiés ou non, émanant des établissements d'enseignement et de recherche français ou étrangers, des laboratoires publics ou privés.

\section{다)(1) $(5$}

Distributed under a Creative Commons Attribution - NonCommerciall 4.0 International 
1 "Understanding biofilm formation in intravascular device-related infections"

3 Christophe Beloin ${ }^{1 *}$, Nuria Fernández-Hidalgo ${ }^{2}$ and David Lebeaux ${ }^{3,4}$

$4 \quad$ 1: Institut Pasteur, Unité de Génétique des Biofilms, Département de Microbiologie, Paris, France

5 2: Servei de Malalties Infeccioses. Hospital Universitari Vall d'Hebron. Universitat Autònoma de 6 Barcelona. Barcelona, Spain.

$7 \quad{ }^{3}:$ Service de Microbiologie, Unité Mobile de Microbiologie Clinique, Assistance Publique-Hôpitaux de 8 Paris, Hôpital Européen Georges Pompidou, Paris, France.

$9 \quad{ }^{4}$ : Université Paris Descartes, Paris, France.

10

11

12

* corresponding author: Christophe Beloin, christophe.beloin@pasteur.fr

13

14 


\section{Introduction}

The use of indwelling devices is constantly increasing in modern medicine. Although they improve patients' care, it is recognised that their use is associated with the risk of infection. Device-related infections represent a significant part of hospital-acquired infections and are due to device contamination by microorganisms subsequently forming biofilms. These biofilms can be defined as sessile communities encased in a self-produced matrix that protects them from external insults including the host immune system and antimicrobial agents. Historically the first description of the involvement of biofilms in a device-related infection was provided in 1982 by the observation of a pacemaker colonised by Staphylococcus aureus [1]. Since then, formation of biofilms has been described in all indwelling devices and is especially problematic in intensive care units (ICU) where intravascular (including intracardiac) devices are extensively used. Among them, intravascular catheters are used for different purposes in ICU including infusion, haemodialysis, parenteral nutrition, hemodynamic monitoring or support such as during extracorporeal membrane oxygenation (ECMO) or extracorporeal life support (ECLS). In part because of their repeated manipulation, the use of such devices is associated with infection incidence densities ranging from 0.8 to 3.7 episodes per 1000 catheter-days, depending on ICU units [2]. Main microorganisms responsible for intravascular catheter colonisation and subsequent infections depend on local epidemiology and type of ICU but mostly include Staphylococcus spp, Gram-negative rods and yeasts. Most of the time, clinical symptoms of intravascular catheter-related infections are unspecific, such as fever, chills or hypotension, and local cutaneous signs such as redness or pain are seen in $\sim 20 \%$ of the cases.

Here we will describe the different steps of bacterial biofilm formation on intravascular catheters and strategies that can be developed to avoid or reduce their clinical consequences (Figure 1). Such a physiopathologic scheme can also be applied to the formation of biofilm on other intravascular devices such as cardiac prosthetic valves or pacemakers.

\section{Targeting early steps of colonisation}

While initial contamination of intravascular catheters can occur through bacterial translocation from the gut (typically in critically ill and oncology patients) or bloodstream infection (BSI) from another infectious source (Figure 1A), the main route of contamination is the patient's skin bacterial flora or healthcare workers' hand manipulating the catheter hub (Figure 1B and C, respectively). In this case, contamination occurs mainly because of suboptimal aseptic measures and can lead to intra- or extraluminal colonisation [3].

Initial events of adhesion on abiotic surfaces such as intravascular catheters that will further lead to colonisation are dependent on electrostatic interactions between bacteria and surfaces as well as more specific interactions between bacterial surface appendages and host proteins that can rapidly cover the implanted material (Figure 1D). These interactions are mediated through different types of adhesins both in Gram-positive and Gram-negative bacteria such as flagella, homo- or heteropolymeric fimbriae and large adhesins [4]. In Gram-negative bacteria, many of these biofilm-promoting factors are activated by cyclic-di-GMP (c-di-GMP), an allosteric activator controlling free-swimming to sessile lifestyle transition [5].

The best prevention approach comes with hand hygiene and skin antisepsis for catheter insertion and handling. Skin disinfection with chlorhexidine-alcohol has been proven to be the more active [6]. If incidence of catheter-related infections is still high, other prophylactic strategies can be proposed including chlorhexidine-impregnated sponges or microbiocides-impregnated catheters such as those containing minocycline-rifampin [7]. While not in clinic yet, devices coated with natural or synthetic antimicrobial peptides might provide in the future novel preventive solutions [8]. In the setting of ICU, as catheters are continuously used, preventive lock therapies are of limited help. The principle of such locks is to inject a small volume of highly concentrated antibiotics in the catheter lumen in order to prevent or eradicate biofilm. One trial demonstrated that a short-course ethanol lock did not prevent dialysis catheter-related infections [9]. Furthermore, the use of such ethanol locks may be associated with catheter clotting and should therefore be carefully used. An alternative to biocidal treatment might be translated in the future into the clinic by the use of anti-adhesive molecules avoiding initial attachment such as coating of catheters with polymers like poly-ethylene-glycols or polysaccharides (methyl-cellulose [10], ulvans) [11], or by interfering with the transition from free-swimming to sessile lifestyle using c-di-GMP inhibitors (for example [12]).

\section{Targeting mature biofilms}


After initial attachment, maturation of biofilm essentially relies on communication between bacteria through "quorum-sensing" (QS) molecules and the production of the biofilm matrix. The latter is composed essentially of water and is structured by various macromolecules such as extra-cellular DNA, polysaccharides and proteins (Figure 1E). This matrix not only governs biofilm architecture but also provides protection against both the immune system and antimicrobial agents by reducing their diffusion. At that stage, pieces of biofilms can shed in the bloodstream, leading to sepsis, septic thrombophlebitis, or distant infections such as infective endocarditis or bone and joint infections (Figure 1F). Growth of biofilms in the lumen of the catheter can also be responsible for catheter clotting limiting its use.

The presence of the matrix within mature biofilms imposes gradients of nutrients, oxygen and waste products leading to an important chemical heterogeneity [13] and thus promotes emergence, at a low frequency, of phenotypic variants including the so-called persisters. Persisters, unlike most of the cells composing the biofilms, can survive to extremely high levels of antimicrobial agents, and are thus considered the main cause of biofilm antibiotic tolerance and of chronic and recurrent infections [14]. The diagnosis of catheter-related BSI (C-RBSI) is established when the same microorganism grows in percutaneous blood cultures and on the catheter tip. It can also be made without removing the catheter by means of the differential time to positivity or quantitative blood cultures techniques [15]. In the last, blood samples from all catheters lumens must be cultured in order to increase sensitivity [16]. Catheter withdrawal and systemic antimicrobials are the cornerstones of C-RBSI treatment. Antibiotic lock therapy plus systemic antimicrobials is an effective and safe strategy to treat uncomplicated CRBSI without catheter removal but should be restricted to long-term central venous catheters in stable patients. As a consequence, it cannot be recommended routinely in ICU patients [17].

In the future, however, some promising approaches might translate into the clinics. For example, together with a systemic treatment, antibiotic adjuvants that destroy or destabilise the matrix and thus weaken the biofilms such as enzymes (DispersinB, DNasel) or cations chelators (EDTA [18]), or molecules that directly target persister cells (sugars, ADEP4, antimicrobial peptides, etc) [19], could be used as short-course catheter locks for catheter salvage.

\section{Conclusion and future challenges.}

Intravascular catheter-related infections remain a major health issue especially in the ICU. Despite promising approaches developed in research laboratories, in part because of molecule development cost issues, limited relevance of some in vitro and in vivo animal models and the severity of patients, the physicians in ICU still have very little options when facing such infections.

When an ICU patient suffers from a C-RBSI, the safest option today remains removal of the colonised catheter. Rapid improvements will probably come from preventive strategies firstly based on enhanced hygiene. The next challenges for researchers will be to develop novel strategies to improve early detection of biofilm formation before any symptoms are visible and to increase knowledge and mitigation of polymicrobial biofilm infections that are now often detected in intravascular catheters and, especially, intracardiac devices. 
Figure 1. Schematic view of biofilm formation on the surface of a central venous catheter.

a Microbial contamination can come from a bloodstream infection (defining an hematogenous contamination) but must most frequently originates from the patient's skin (because of a lack of skin antisepsis) (b) or from the catheter hub (c). These last two routes of contamination lead to extraluminal and endoluminal colonisation, respectively. After contamination, reversible and irreversible adhesion allow the microorganism to stick to the surface of the catheter (d). Microorganisms multiply, form a microcolony and then evolve to mature biofilm (e) through matrix production and quorum-sensing signals. $\mathbf{f}$ Lastly, dispersal of biofilm pieces or individual cells is responsible for bloodstream infection and subsequent infection dissemination.

\section{Catheter hub}

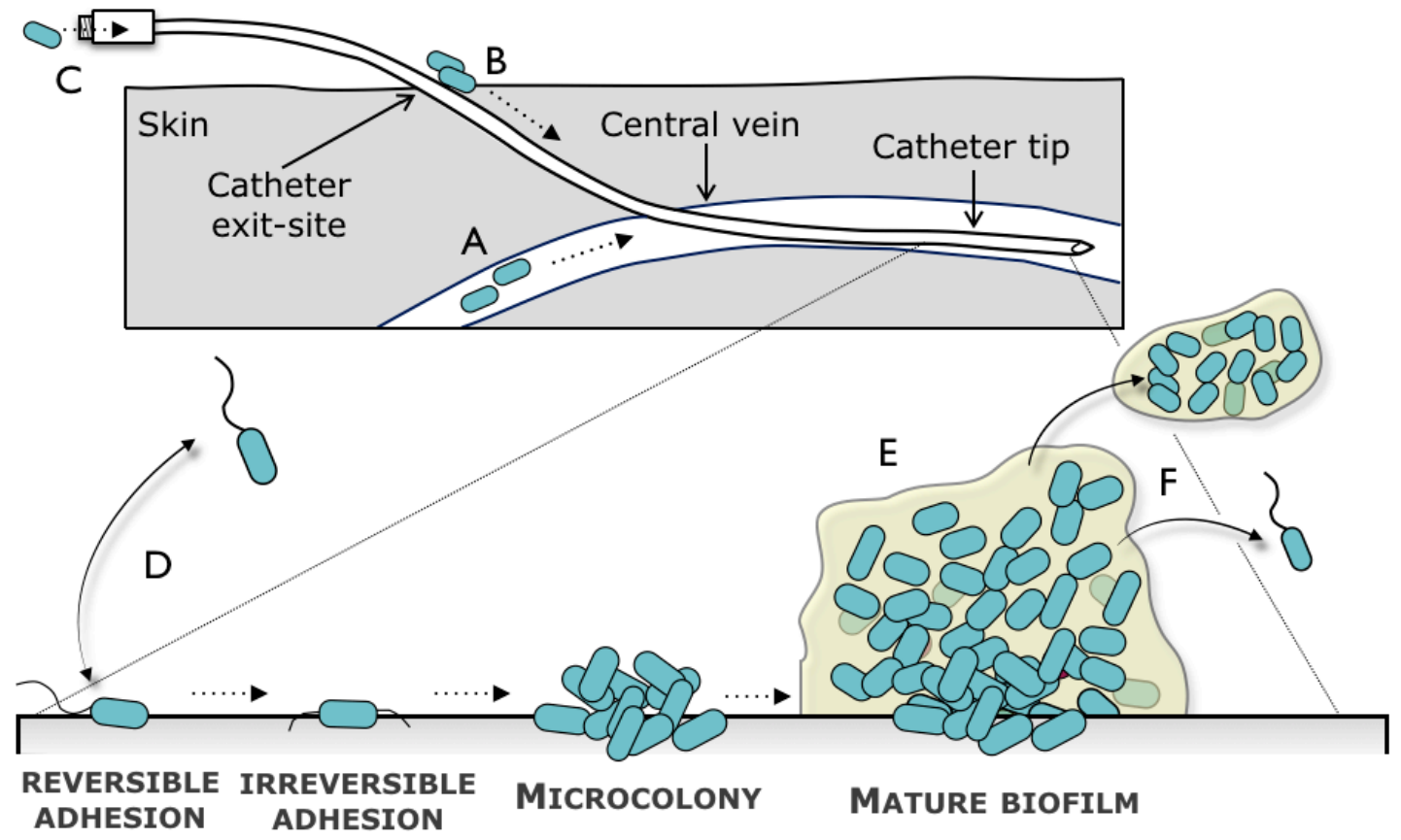


Conflicts of interest. The authors declare no conflicts of interest.

\section{References}

1. Marrie TJ, Nelligan J, Costerton JW, (1982) A scanning and transmission electron microscopic study of an infected endocardial pacemaker lead. Circulation 66: 1339-1341

2. Dudeck MA, Horan TC, Peterson KD, Allen-Bridson K, Morrell G, Anttila A, Pollock DA, Edwards JR, (2013) National Healthcare Safety Network report, data summary for 2011, device-associated module. American journal of infection control 41: 286-300

3. Pronovost P, Needham D, Berenholtz S, Sinopoli D, Chu H, Cosgrove S, Sexton B, Hyzy R, Welsh R, Roth G, Bander J, Kepros J, Goeschel C, (2006) An intervention to decrease catheter-related bloodstream infections in the ICU. The New England journal of medicine 355: 2725-2732

4. Chagnot C, Zorgani MA, Astruc T, Desvaux M, (2013) Proteinaceous determinants of surface colonization in bacteria: bacterial adhesion and biofilm formation from a protein secretion perspective. Frontiers in microbiology 4: 303

5. Valentini M, Filloux A, (2016) Biofilms and Cyclic di-GMP (c-di-GMP) Signaling: Lessons from Pseudomonas aeruginosa and Other Bacteria. The Journal of biological chemistry 291: 12547-12555

6. Mimoz O, Lucet JC, Kerforne T, Pascal J, Souweine B, Goudet V, Mercat A, Bouadma L, Lasocki S, Alfandari S, Friggeri A, Wallet F, Allou N, Ruckly S, Balayn D, Lepape A, Timsit JF, investigators Ct, (2015) Skin antisepsis with chlorhexidine-alcohol versus povidone iodinealcohol, with and without skin scrubbing, for prevention of intravascular-catheter-related infection (CLEAN): an open-label, multicentre, randomised, controlled, two-by-two factorial trial. Lancet 386: 2069-2077

7. Schwebel C, Lucet JC, Vesin A, Arrault X, Calvino-Gunther S, Bouadma L, Timsit JF, (2012) Economic evaluation of chlorhexidine-impregnated sponges for preventing catheter-related infections in critically ill adults in the Dressing Study. Critical care medicine 40: 11-17

8. Batoni G, Maisetta G, Esin S, (2016) Antimicrobial peptides and their interaction with biofilms of medically relevant bacteria. Biochimica et biophysica acta 1858: 1044-1060

9. Souweine B, Lautrette A, Gruson D, Canet E, Klouche K, Argaud L, Bohe J, GarrousteOrgeas M, Mariat C, Vincent F, Cayot S, Cointault O, Lepape A, Guelon D, Darmon M, Vesin A, Caillot N, Schwebel C, Boyer A, Azoulay E, Bouadma L, Timsit JF, (2015) Ethanol lock and risk of hemodialysis catheter infection in critically ill patients. A randomized controlled trial. American journal of respiratory and critical care medicine 191: 1024-1032

10. Chauhan A, Bernardin A, Mussard W, Kriegel I, Esteve M, Ghigo JM, Beloin C, Semetey V, (2014) Preventing biofilm formation and associated occlusion by biomimetic glycocalyxlike polymer in central venous catheters. The Journal of infectious diseases 210: 1347-1356

11. Junter GA, Thebault P, Lebrun L, (2016) Polysaccharide-based antibiofilm surfaces. Acta biomaterialia 30: 13-25

12. Sambanthamoorthy K, Luo C, Pattabiraman N, Feng X, Koestler B, Waters CM, Palys TJ, (2014) Identification of small molecules inhibiting diguanylate cyclases to control bacterial biofilm development. Biofouling 30: 17-28

13. Stewart PS, Franklin MJ, (2008) Physiological heterogeneity in biofilms. Nature reviews Microbiology 6: 199-210

14. Lebeaux D, Ghigo JM, Beloin C, (2014) Biofilm-related infections: bridging the gap between clinical management and fundamental aspects of recalcitrance toward antibiotics. Microbiology and molecular biology reviews : MMBR 78: 510-543

15. Mermel LA, Allon M, Bouza E, Craven DE, Flynn P, O'Grady NP, Raad, II, Rijnders BJ, Sherertz RJ, Warren DK, (2009) Clinical practice guidelines for the diagnosis and management of intravascular catheter-related infection: 2009 Update by the Infectious Diseases Society of America. Clinical infectious diseases : an official publication of the Infectious Diseases Society of America 49: 1-45

16. Planes AM, Calleja R, Bernet A, Campins-Marti M, Almirante B, Pumarola T, FernandezHidalgo N, (2016) Evaluation of the usefulness of a quantitative blood culture in the diagnosis of catheter-related bloodstream infection: Comparative analysis of two periods (2002 and 2012). Enfermedades infecciosas y microbiologia clinica

17. Fernandez-Hidalgo N, Almirante B, (2014) Antibiotic-lock therapy: a clinical viewpoint. Expert review of anti-infective therapy 12: 117-129 
18. Chauhan A, Lebeaux D, Ghigo JM, Beloin C, (2012) Full and broad-spectrum in vivo eradication of catheter-associated biofilms using gentamicin-EDTA antibiotic lock therapy. Antimicrobial agents and chemotherapy 56: 6310-6318

19. Beloin C, Renard S, Ghigo JM, Lebeaux D, (2014) Novel approaches to combat bacterial biofilms. Current opinion in pharmacology 18: 61-68 